\title{
Widening the Reach of Bioethics Scholarship
}

\author{
Graeme T. Laurie ${ }^{1}$
}

Published online: 13 September 2021

() National University of Singapore and Springer Nature Singapore Pte Ltd. 2021

As suggested by its name, the Asian Bioethics Review has determinedly been committed to highlighting and celebrating bioethics scholarship in the Asian region ever since the establishment of the journal in 2009. But this commitment brings multiple challenges. First, Asia is an incredibly vast and diverse place, both geographically and culturally. Finding ways to capture and reflect this through publications in the journal has been an on-going struggle. Second, there is a risk that bioethics scholars seeking an outlet for their work might imagine that the Asian Bioethics Review is only or exclusively interested in work from Asia or about Asia. But this is most certainly not the case, nor has it ever been so. The dual undertakings of building capacity within Asia while also providing an international, high-quality forum to express and exchange original ideas on all aspects of bioethics are indeed mutually dependent, rather than being mutually exclusive. Building capacity within Asia aims to contribute to an international forum, while simultaneously providing an international forum that is supportive of building capacity in Asia. Finally, as explored in early discussions in the inaugural issue of the journal (https://abrjournal.wordpress. com/volumes-10-11-12/abr000/), there is a further risk of perpetuating a crude and unreflective West v Rest approach to thinking about values in societies, or inadvertently suggesting that there is such a thing as a unitary conception of "Asian bioethics". However, we hope and believe that the journal has done a good job to date in countering any such tendencies in bioethical scholarship. Indeed, the journal provides the ideal locus to engage these issues head-on and to showcase work from across the globe.

The papers in this issue demonstrate very well how the Asian Bioethics Review seeks to rise to the challenges of its own remit. Herein, the reader will find a celebration of geographical and cultural diversity from within the Asian region; there are also examples of robust empirical work that help us to understand which values, motivations, beliefs and ways of thinking are driving some behaviours within Asia in response to novel bioethical issues; by the same token, there is a lived experience account of a bioethics consultation service dealing with COVID-19 that might have considerable resonance for bioethics activists across the globe dealing with the

Graeme T. Laurie

graeme.laurie@ed.ac.uk

1 Edinburgh Law School, The University of Edinburgh, Edinburgh, UK 
pandemic; finally, we include a medico-legal example of a jurisdiction within Asia whose legal tradition draws heavily from Anglo-American legal thinking. The analysis shows how cross-fertilisation of ideas happens between legal systems around the world when tackling common jurisprudential issues, while at the same time, local considerations mould and shape the particular responses that are required for law to be both effective and ethically sensitive in a given context.

The first challenge mentioned in this Editorial is that pertaining to the considerable geographical and cultural diversity that is Asia. Regular readers of this journal will know that coverage has been uneven in terms of attracting contributions from the full range of countries that make up the Asian region. It is for this reason that we are particularly honoured to publish our first paper that pertains to Bhutan, or more specifically to the plight of Bhutanese refugees in the face of the COVID-19 pandemic. Thus, McGuire et al. (https://doi.org/10.1007/s41649-021-00183-1) offer the first of two papers to be published in two consecutive issues of the journal that examine the mental health needs of resettled Bhutanese refugees in the USA. In this first paper, the authors give an account of the history and reported experiences of members of the Nepali-speaking Bhutanese population who have participated in other pieces of research. Through a qualitative systematic review of the literature and a comparison of the experiences of Bhutanese refugees and other refugee populations going through resettlement processes, this paper reveals both specific social determinants impacting mental health for the Bhutanese refugees as well as similarities across refugee groups. This evidence base lays the foundation for a public health justice framework and recommendations that form the second paper that will appear in the journal in January 2022. This coincides with a change to our publishing schedule: issues will now appear in January, April, July and October of each year.

The Asian Bioethics Review has made extensive efforts to publish accounts relating to various country responses to the COVID-19 pandemic, analysed and assessed through various critical bioethical lenses. However, the experiences of citizens themselves have featured less prominently and it is for this reason that the paper by Siddiqui and Qamar (https://link.springer.com/article/10.1007/s41649021-00181-3) is particularly important and valuable. It captures evidence from Pakistani citizens from April 2020, very shortly after the pandemic was announced by the World Health Organization on 11 March 2020. As well as recounting what are-by now-some globally common and understandable reactions to the threat of infection and to government-imposed restrictions on liberty and free movement, this paper also provides insights about the influences of beliefs about what the pandemic might represent and how people of the Islamic faith should respond. The findings show that religious faith provided an important personal coping mechanism for many during those early days. Equally, the paper raises important wider questions about how to strike a balance between the religious interpretation of scriptural sources and the public health implications and diktats of dealing with a pandemic such as COVID-19 in countries that follow Islam, already being discussed elsewhere (Shabana 2021).

In a further example of empirical research that reveals insights to citizens' moral awareness, the paper by Ghotbi and Ho (https://link.springer.com/article/ 
10.1007/s41649-021-00182-2) builds on their earlier published work (Ghotbi et al. 2021) to examine the attitudes of college students in Japan towards artificial intelligence (AI). In contrast to much of the work published to date on the ethics of AI, which is often engaged in discussion of the "rightness" or "wrongness" of developments in AI itself and potential applications, this extensive study of almost 500 college students in Japan-two-thirds of whom where non-Japanese citizens-reveals a range of concerns prioritised from a list of ethical issues provided by the authors and on which the students were invited to reflect critically. The results can be read in the paper itself; the overarching conclusion is that robust moral awareness among this cohort was rather limited, and the recommendation is made that more curriculum development is required on the ethics of AI.

The final original article in this issue is by Tang (https://link.springer.com/ article/10.1007/s41649-021-00175-1), and offers a medico-legal analysis of pharmaceutical dispensing errors in Hong Kong. As outlined above, this paper is a very good example of how legal systems influence and infect each other across the globe, while it also provides a well-grounded normative case for discussing how Hong Kong should respond to liability arising from errors in dispensing medicine against the backdrop of a discussion of local developments, regulatory approaches and Hong Kong's own cultural context.

The two perspective papers in this issue continue the sub-theme of personal reflections and lived experiences of dealing with bioethical issues. Thus, the paper by Salupo et al. (https://link.springer.com/article/10.1007/s41649-02100177-z) presents the experiences of a Bioethics Consultation Service in an urban hospital in the USA in the first nine months of the COVID-19 pandemic, reflecting to some extent the paper by Siddiqui and Qamar in capturing early experience of reacting to this new global threat. As well as noting a significant increase in the incidence of bioethics consults and an account of the nature of the consults themselves, the paper is analytically valuable for its reflections on how the service was affected by the advent of the pandemic and for what these experiences mean for our understandings of vulnerability during such times of crisis.

Finally, the paper by Toh et al. (https://doi.org/10.1007/s41649-021-00180-4) reports on religious perspectives pertaining to precision medicine in Singapore in the wake of the launch of the National Precision Medicine Strategy. In something of a variation on more standard engagement exercises with publics, the authors held a workshop to seek the views of religious authorities in Singapore, inviting them to share their perspectives on precision medicine more generally, and on data sharing more specifically with public and private sectors organisations. Again, without wishing to pre-empt the reporting of the results in the article itself, this paper is a valuable contribution to furthering the remit of the Asian Bioethics Review as an illustration of how many commonly shared values and concerns influence attitudes towards novel bioethical issues and technological developments. It is further evidence that we may have far more in common between us than what might potentially divide us. 


\section{References}

Ghotbi, Nader, Manh Tung Ho, and Peter Mantello. 2021. Attitude of college students towards ethical issues of artificial intelligence in an international university in Japan. AI \& Society. https://doi.org/ 10.1007/s00146-021-01168-2.

Shabana, Ayman. 2021. From the plague to the coronavirus: Islamic ethics and responses to the COVID19 pandemic. Journal of Islamic Ethics. https://doi.org/10.1163/24685542-12340060.

Publisher's Note Springer Nature remains neutral with regard to jurisdictional claims in published maps and institutional affiliations. 